\title{
On the effectiveness of reward-based policies: Are we using the proper concept of tax reward?
}

\author{
Gaetano Lisi* \\ eCampus University, Italy
}

Received: 24 December 2020

Revised: 11 August 2021

Accepted: 9 September 2021

\begin{abstract}
Tax reward is considered an important element of fiscal policies for spurring tax compliance. Empirically, however, the effectiveness of reward-based policies is not confirmed. This short theoretical paper suggests that this discrepancy might just be due to the use of a "wrong" concept of tax reward in empirical and experimental works.
\end{abstract}

Keywords: Tax reward; Fiscal policy; Tax compliance

JEL Classification Codes: H24, H25, H26, K34

\section{Introduction}

Tax reward is a key component of fiscal policies for fighting tax evasion (see, e.g., Feld et al., 2006; Feld and Frey, 2007; Murphy, 2012; Brockmann et al., 2016). Nevertheless, the effectiveness of reward-based policies is not empirically confirmed. At least until now, in fact, there are not clear empirical findings about the positive effect of tax reward on tax compliance decisions (Kastlunger et al., 2011; Bazart and Pickhardt, 2011; Brockmann et al., 2016; Fochmann and Kroll, 2016).

These ambiguous empirical results might just be due to the use of a "wrong" concept of tax reward. Indeed, empirical and experimental works focus on two main concepts of reward (see, e.g., Frey et al., 2004; Brockmann et al., 2016): "lucky reward" (that links tax compliance to the chance of winning in a lottery) and "donation reward" or "immaterial reward" (that allows compliant taxpayers to take part, to some extent, to public spending). Unfortunately, the concept of "lucky reward" is not directly connected with honest tax behaviours (winning the lottery is, in fact, a matter of luck); while the concept of "donation reward" is quite difficult to achieve and perhaps hazardous (since, of course, honesty does not imply competence in deciding how to use public spending efficiently).

In the spirit of Falkinger and Walther (1991) seminal work, instead, a proper (and simple) concept of reward should refer to the exact opposite of the penalty. In short, if the fine represents the punishment of dishonest tax behaviours, the reward should represent the award for honest

\footnotetext{
*Corresponding author. E-mail: gaetano.lisi@uniecampus.it.
}

Citation: Lisi, G. (2022) On the effectiveness of reward-based policies: Are we using the proper concept of tax reward?, Economics and Business Letters, 11(1), 41-45.

DOI: $10.17811 /$ ebl.11.1.2022.41-45 
tax behaviours. This theoretical paper, therefore, introduces into the standard theoretical model of tax evasion" a tax reward in the simplest form of a "negative penalty" (positive amount of money) in case of no tax evasion, instead of no penalty (as in the standard model). Such a reward makes the tax system fairer (see Section 2), thus encouraging honest tax behaviours. As a result, a suggestion for empirical and experimental works emerges from this theoretical model: a positive effect of tax reward on tax compliance can be found by using a proper concept of award.

\section{The theoretical model}

A tax reward in the simplest form of a "negative penalty" (positive amount of money in case of no tax evasion) is introduced into the standard economic model of taxpayer's behaviour. Precisely, individuals that declare all their income and are successfully audited will receive the tax reward $(b>0){ }^{2}$ The utility function $(U)$ of a representative taxpayer, therefore, becomes the following: ${ }^{3}$

$$
U=y-y^{D} \cdot \tau-\rho \cdot\left[\left(y-y^{D}\right)^{\varphi}-b \cdot\left(\frac{y^{D}}{y}\right)^{k}\right]
$$

where $y$ is true (net) income; $y^{D}$ is declared income; $\tau$ is the tax rate (a "flat tax", for the sake of simplicity); $\rho$ is the monitoring rate; $\left(y-y^{D}\right)$ is the income tax evasion; $\left(y-y^{D}\right)^{\varphi}$ is the penalty component, with $\varphi>1 ; k$ is a remarkably high number such that the reward component $b \cdot\left(\frac{y^{D}}{y}\right)^{k}$ approaches to zero if $y$ is higher than $y^{D}$; whereas, the reward component is positive but small if $y^{D}$ is only slightly lower than $y$, i.e., $y \approx y^{D}{ }^{4}$ Of course, the entire reward is provided for (totally) honest taxpayers, namely those who declare all their income $\left(y=y^{D}\right)$.

As a result, when $y>y^{D}$, the reward component disappears and only the penalty applies (as in the standard economic model of tax evasion); whereas, in a totally honest world, when $y=$ $y^{D}$, the penalty disappears and only the reward applies. In the intermediate case, instead, where $y^{D}$ is only slightly lower than $y$, both penalty and reward apply (see Table 1).

Table 1. Taxpayer's utility function.

\begin{tabular}{ccc}
\hline \hline Utility function & When & Mathematical formula \\
\hline \hline with penalty and reward & $y \approx y^{D}$ & $U=y-y^{D} \cdot \tau-\rho \cdot\left(y-y^{D}\right)^{\varphi}+\rho \cdot b$ \\
& & $\cdot\left(\frac{y^{D}}{y}\right)^{k}$ \\
standard (only penalty) & $y>y^{D}$ & $U=y-y^{D} \cdot \tau-\rho \cdot\left(y-y^{D}\right)^{\varphi}$ \\
honest taxpayers (only re- & $y=y^{D}$ & $U=y \cdot(1-\tau)+\rho \cdot b$ \\
ward) & & \\
\hline \hline
\end{tabular}

\footnotetext{
${ }^{1}$ For an overview on these models, see Sandmo (2005).

${ }^{2}$ In order to remove some element of luck in the monitoring (since only audited honest taxpayers will be rewarded), the model assumes that the tax benefits $(b)$ depend (positively) on the "years of honesty", namely, the number of years in which the taxpayer has declared the entire income. This implies that the "habitual" honest taxpayers will get more benefits in the event of an audit.

${ }^{3}$ For the sake of simplicity, risk neutrality is assumed on the taxpayer's side (Srinivasan, 1973) instead of risk aversion (Allingham and Sandmo, 1972).

${ }^{4}$ Regarding the choice of the functional form of the benefit, it is straightforward to show that the reward component cannot be modeled as the penalty component. If the reward component is a function of the difference between $y^{D}$ and $y$, in fact, it becomes zero when $y^{D}=y$.
} 
In the presence of both penalty and reward, an increase in the declared income has a further positive effect on the taxpayer's utility function, namely an increase in reward (besides a reduction in penalty):

$$
\frac{d U}{d y^{D}}=-\tau+\rho \cdot \varphi \cdot\left(y-y^{D}\right)^{\varphi-1}+\rho \cdot b \cdot \frac{k}{y} \cdot\left(\frac{y^{D}}{y}\right)^{k-1}
$$

It follows that, in the absence of a heavy tax burden (a remarkably high marginal tax rate $\tau$ ), the increase in the declared income has a positive effect on the taxpayer's utility function, viz. ${ }^{5}$

$$
\begin{gathered}
\frac{d U}{d y^{D}}>0 \\
\text { if } \varphi \cdot\left(y-y^{D}\right)^{\varphi-1}+b \cdot \frac{k}{y} \cdot\left(\frac{y^{D}}{y}\right)^{k-1}>\frac{\tau}{\rho}
\end{gathered}
$$

In a totally honest world, the previous condition results in a sufficiently high reward:

$$
b>\frac{\tau}{\rho} \cdot \frac{y}{k}
$$

Intuitively, the larger the tax resources $(\tau \cdot y)$, the higher should be the reward.

In the extended model with tax reward, therefore, there is not an optimum level of declared income for taxpayer (as in the standard economic model of tax evasion), but rather an upper limit exists, namely $y=y^{D}$. Indeed, this equality should represent one of the main targets of tax authorities.

The key role of tax reward in enhancing tax compliance can be shown in the intermediate and quite common case where $y^{D}$ is lower than $y$, but not so much as to warrant a penalty, namely $y \approx y^{D}$. Precisely, $y^{D}$ can be only slightly lower than $y$ for formal errors in filling in the tax return, rather than willful evasion.

In the standard economic model of tax evasion, of course, only the penalty applies. Regardless of its size, that depends on the parameter $\varphi>1$, the penalty has anyway negative psychological effects, since it applies also to potential honest taxpayers, namely in the case $y \approx y^{D}$. Thus, penalties and fines could discourage future honest tax behaviours (see, e.g., Kirchler et al., 2010).

Instead, in the utility function with penalty and reward, when $y \approx y^{D}$, the reward component acts to compensate the penalty component. Concisely, if $y^{D}$ is only slightly lower than $y$, tax system applies both the penalty and the reward, thus making the tax system fairer. A simple simulation can depict this situation. First of all, we define $y \approx y^{D}$ a situation where the difference between the actual income and the declared income is equal to or less than $5 \%$, viz.:

$$
1-\frac{y^{D}}{y} \leq 5 \%
$$

or

$$
\left(y-y^{D}\right) \leq 5 \% \cdot y
$$

In the event of an audit (that occurs with probability $\rho$ ), the difference between the penalty and the reward decreases as the declared income increases until the reward becomes greater than the penalty when the taxpayer declares $99 \%$ of the income (see Table 2).

Eventually, tax reward acts as a "tax moderator" and, thus, it should be a perfect complement of penalties and fines. This result provides a suggestion for empirical works: by using a (proper) concept of award, namely the exact opposite of the penalty, a positive effect of tax reward on tax compliance should be found. The theoretical explanation is exactly the role of reward in making the tax system fairer.

\footnotetext{
${ }^{5}$ A heavy tax burden could lead to a widespread tax evasion, but a widespread tax evasion should lead to an extensive monitoring rate. Concisely, a higher $\tau$ calls a higher $\rho$.
} 
Table 2. Penalty vs Reward.

\begin{tabular}{ccc}
\hline \hline $\boldsymbol{1}-\left(\frac{\boldsymbol{y}^{\boldsymbol{D}}}{\boldsymbol{y}}\right)$ & $\left(\boldsymbol{y}-\boldsymbol{y}^{\boldsymbol{D}}\right)^{\boldsymbol{\varphi}}$ & $\boldsymbol{b} \cdot\left(\frac{\boldsymbol{y}^{\boldsymbol{D}}}{\boldsymbol{y}}\right)^{\boldsymbol{k}}$ \\
\hline $5 \%$ & $1,995.26$ & 11.84 \\
$4 \%$ & $1,560.99$ & 33.74 \\
$3 \%$ & $1,137.54$ & 95.11 \\
$2 \%$ & 728.23 & 265.24 \\
$1 \%$ & 339.73 & 732.06 \\
\hline \hline
\end{tabular}

Concisely, the positive effect of tax reward on tax compliance is based on the following virtuous circle:

$(+)$ tax reward $\rightarrow(+)$ tax equity $\rightarrow(+)$ tax morale $\rightarrow(+)$ tax compliance

Indeed, this paper shows the first step of this virtuous circle (the "missing piece of the puzzle"), since the positive relation between tax equity and tax morale (see. e.g., Castañeda, 2019), as well as the positive relation between tax morale and tax compliance (see, e.g., Cummings et al., 2009; Molero and Pujol, 2012) are widely recognised in the related literature.

\section{Conclusions}

Tax reward is considered an important element of fiscal policies for spurring tax compliance. At least until now, however, there are not clear empirical findings about the positive effect of tax reward on tax compliance decisions.

This short theoretical paper suggests that with a right concept of tax reward, namely the exact opposite of the penalty, a positive effect of tax reward on tax compliance could be found. Precisely, the model is a simple extension of standard models of tax compliance that adds a tax reward in the simplest form of a "negative penalty" (positive amount of money) in case of no tax evasion, instead of no penalty (as in the standard model).

The key insight of the model is that when income is only slightly underreported - which may be due to filing errors and not willful evasion - a small reward partially offsets the penalty. Such a mechanism may prevent the negative psychological effects of penalties on honest taxpayers. Furthermore, such a reward makes the tax system fairer, thus encouraging honest tax behaviours.

As a result, a suggestion for empirical and experimental works emerges from this theoretical model: it needs to use a concept of tax reward directly connected with honest tax behaviours instead of the concepts of "lucky reward" and "donation reward".

A real and recent example of tax reward proposed in this paper for enhancing tax compliance is given by Italy, where tax administration recognises several types of tax benefits, in consideration of the degree of fiscal reliability of taxpayers deriving from the application of specific indices, the so-called "synthetic indices of fiscal reliability". ${ }^{6}$ Obviously, the higher the index, the higher the degree of fiscal reliability of taxpayers and thus the greater the tax benefits.

\footnotetext{
${ }^{6}$ Precisely, law decree n. 50 of 24 April 2017, article 9 bis, paragraph 11 from letter $a$ to $f$.
} 


\section{References}

Allingham M.G., and Sandmo A. (1972). Income Tax Evasion: A Theoretical Analysis. Journal of Public Economics, 1, 3-4, 323-338.

Bazart C., and Pickhardt M. (2011). Fighting Income Tax Evasion with Positive Rewards. Public Finance Review, 39, 1, 124-149.

Brockmann H., Genschel P., and Seelkopf L. (2016). Happy taxation increasing tax compliance through positive rewards. Journal of Public Policy, 36, 3, 381-406.

Castañeda V. M. (2019). Tax Equity and its Association with Fiscal Morale, International Public Management Journal, DOI: 10.1080/10967494.2019.1671926.

Cummings R. G., Martinez-Vazquez J., McKee M., and Torgler B. (2009). Tax Morale Affects Tax Compliance: Evidence from Surveys and an Artefactual Field Experiment. Journal of Economic Behaviour and Organization, 70, 447-57.

Falkinger J., and Walther H. (1991). Rewards versus penalties: On a new policy against tax evasion. Public Finance Quarterly, 19, 1, 67-79.

Feld L. P., and Frey B. S. (2007). Tax Compliance as the Result of a Psychological Tax Contract: The Role of Incentives and Responsive Regulation. Law and Policy, 29, 1, 102-20.

Feld L. P., Frey B. S., and Torgler B. (2006). Rewarding Honest Taxpayers? in Managing and Maintaining Compliance, Elffers H. and und Wim Huisman P. V. (eds), Den Haag: Boom Legal Publishers, 45-61.

Fochmann M., and Kroll E. B. (2016). The Effects of Rewards on Tax Compliance Decisions. Journal of Economic Psychology 52, C, 38-55.

Frey B. S., Benz M., and Stutzer A. (2004) Introducing Procedural Utility: Not Only What, but Also How Matters. Journal of Institutional and Theoretical Economics, 160, 3, 377-401.

Kastlunger B., Muehlbacher S., Kirchler E., and Mittone L. (2011). What Goes Around Comes Around? Experimental Evidence of the Effect of Rewards on Tax Compliance. Public Finance Review, 39, 1, 150-167.

Kirchler E., Mühlbacher S., Kastlunger B., and Wahl I. (2010). Why Pay Taxes? A Review of Tax Compliance Decisions, in Alm J., Martinez-Vazques J., and Torgler B. (eds), Developing Alternative Frameworks for Explaining Tax Compliance. Routledge, London, pp. 15-31.

Molero J.C. and Pujol F. (2012). Walking Inside the Potential Tax Evader's Mind: Tax Morale Does Matter. Journal of Business Ethics, 105, 2, 151-162.

Murphy R. (2012). Closing the European Tax Gap. A report for Group of the Progressive Alliance of Socialists \& Democrats in the European Parliament, Norfolk: Tax Research LLP.

Sandmo A. (2005). The Theory of Tax Evasion: A Retrospective View. National Tax Journal, $58,4643-663$.

Srinivasan T. N. (1973). Tax evasion: A model. Journal of Public Economics, 2, 4, 339-346. 